\title{
Nanoliposome-Encapsulated Phenolic Rich Fraction From Alcea Rosea as a Dietary Phytobiotic in Mice Challenged by Escherichia Coli
}

Niloofar Hassirian

Islamic Azad University Mashhad Branch

Ehsan Karimi ( $\nabla$ ehsankarimi@mshdiau.ac.ir)

Islamic Azad University Mashhad Branch https://orcid.org/0000-0002-5011-9611

Ehsan Oskoueian

ABRII: Agricultural Biotechnology Research Institute of Iran

\section{Research Article}

Keywords: Phytogenic, phytobiotic, enteropathogen, natural antibiotic, antibiotic replacing agent, encapsulation

Posted Date: October 1st, 2021

DOl: https://doi.org/10.21203/rs.3.rs-741195/v2

License: (9) This work is licensed under a Creative Commons Attribution 4.0 International License. Read Full License

Version of Record: A version of this preprint was published at Annals of Microbiology on February 21 st, 2022. See the published version at https://doi.org/10.1186/s13213-022-01665-9. 


\section{Abstract \\ Purpose}

This research was performed to evaluate the antibacterial and health-promoting potentials of the nanoliposome-encapsulated phenolic rich fraction (PRF) from Alcea rosea leaves as a dietary phytobiotic in mice challenged by enteropathogenic Escherichia coli (E. coil; 0157: H7).

\section{Method:}

The PEF was encapsulated in nanoliposomes (PEF-NLs) and the phenolic profiling of PEF-NLs was confirmed by HPLC. Then 40 white male balb/c mice at four treatment groups were provided and antibacterial potential of PEF-NLs were assessed by measuring the mice blood parameters and liver lipid peroxidation in mice infected by E. coli. Finally, the expression of cyclooxygenase 2 (COX2), inducible nitric oxide synthase (iNOS), superoxide dismutase (SOD) and glutathione peroxidase (GPx) were determined in mice's ileum tissues. Meanwhile, relative fold changes in the ileum population of $E$. coli was analyzed using Real time PCR.

\section{Results}

The overall results demonstrated that the nanoliposome-loaded PRF contained gallic acid, salicylic acid, pyrogallol, cinnamic acid, catechin, naringin, ferulic acid. The E. coil challenge in mice impaired the weight gain, food intake, liver enzymes, lipid peroxidation, morphometric characteristics of the ileum, upregulated the inflammatory genes (COX2, iNOS), down-regulated the antioxidant-related genes (SOD and GPx) and increased the population of E. coil in the ileum. The dietary inclusion of nonencapsulated PRF and nanoliposome-encapsulated PRF at the concentration of $10 \mathrm{mg} \mathrm{TPC} / \mathrm{kg} \mathrm{BW} /$ day improved these parameters however the nanoliposome-encapsulated PRF appeared to be more effective as compared to nonencapsulated PRF in improving the health parameters in mice.

\section{Conclusion}

Consequently, the nanoliposome-encapsulated PRF could play a critical role as a promising phytobiotic against $E$. coil infection in mice.

\section{Background}

Various antibiotics such as $\beta$-lactams, chloramphenicol, tetraglyclines, aminoglycosides, macrolides, glycopeptides, quinolones, streptogramins, oxazolidinones, lipopeptides and mutilins have been developed to cure infectious diseases (Fischbach and Walsh 2009). Infectious diseases are increasingly an important public health issue. They are among the major causes of death worldwide. The increase is 
mainly attributed to the development of antibiotic-resistant strains such as Pseudomonas aeruginosa, Escherichia coli (E. coil), Proteus vulgaris, Staphylococcus aureus, Shigella dysenteriae, Salmonella typhi and many more (Hwang et al. 2017; Vadhana et al. 2015). The impact of antibiotic resistance such as the rapid increase in the cost of drugs and increase in morbidity and mortality (Friedman et al. 2016; Frieri et al. 2017) has spearheaded the search for new alternative sources of antimicrobial agents that are effective, cheap, accessible and possess few or no undesirable side effects such is bioactive constitutes of plants (Górniak et al. 2019; Gutiérrez-del-Río et al. 2018; Mostafa et al. 2018).

Several studies have been confirmed the natural products possess higher chemical novelty than chemically synthesized products and thus this fact has led to the search of active compounds in plants including flavonoid and phenolic compounds. These compounds have been reported to be potentially significant in therapeutic applications as antimicrobial agents. They offer major opportunities for finding novel low molecular weight molecules that are active against microbes (Anand et al. 2019; Hadi et al. 2017).

Alcea rosea L. (A. rosea) belongs to the family of Malvaceae and is a famous and common name as Hollyhock. It is an ornamental plant that is widely grown in the eastern Mediterranean to central Asia (Khoshnamvand et al. 2019). Most of the subspecies have been reported mainly found in Iran and Turkey (Azab 2017). Different aerial parts of plants including seed, root, leave and flower has been applied in traditional medicine like irritated stomach, throat pain, fever, kidney pain, and antimicrobial and antiinflammatory agent (Abdel-salam et al. 2018; Azab 2017). Most of these biological properties in this plant related to the natural bioactive compound especially phenolic compounds. Phenolic compounds consider as abundant and interesting micronutrients due to its outstanding pharmaceutical properties such as natural antioxidant and antimicrobial potential (Acosta-Estrada et al. 2014; Cianciosi et al. 2018). Despite their wide range of biological potentials of phenolic compounds, the low water solubility and poor absorption are the main problems that appear to remain difficult to be employed clinically. The encapsulation using liposomal technology as carriers aimed at enhancing the bioavailability of pharmaceuticals and nutraceuticals benefits of polyphenols (Aditya et al. 2017).

Liposomes consist of one or more spherical lipid bilayers encapsulating bioactive molecules. They can entrap both lipophilic and hydrophilic molecules in their unique individual structure (Aditya et al. 2017). In such a way that lipophilic molecules are inserted into the phospholipid bilayer membrane, and hydrophilic molecules are encapsulated into the aqueous center of the liposome. In other words, the nanoliposomes' internal compartment is filled with a polar liquid media such as a buffer or water containing dissolved hydrophilic compounds (Emami et al. 2016). The nano-scaled liposomes called nanoliposomes as the targeted-drug delivery systems are the most applicable nano-carriers in the pharmaceutical industry. They have successfully improved the therapeutics' efficiency in a wide range of biomedical applications. Nanoliposomes facilitate the cellular uptake of their contents and efficiently stabilize them (Ozkan et al. 2019; Salimi 2018). This research was performed to synthesis the nanoliposome-encapsulated phenolic rich fraction from $A$. rosea and to evaluate its antibacterial and health-promoting activities in mice challenged by enteropathogenic E. coli (0157: $\mathrm{H} 7)$. 


\section{Results And Discussion}

\section{Fractionation and total phenolic determination}

The fractionation with different polarity solvents resulted in the extraction of most of the phenolic compounds from leaves of $A$. rosea in different quantities which the highest phenolic compounds detected in ethyl acetate fraction $26.1 \pm 4.36$ followed by n-butanol $(16.7 \pm 3.29)>$ water $(12.6 \pm 3.94)>$ chloroform $(8.3 \pm 2.76)>$ hexane $(7.5 \pm 2.63) \mathrm{mg} \mathrm{GAE} / \mathrm{g} \mathrm{DW}$ of extract, respectively. The ethyl acetate fraction appeared to be the fraction with the highest content of phenolic compounds hence named as a phenolic rich fraction (PRF) and was used for further experiments. The earlier studies observed the highest phenolic concentration in the ethyl acetate fraction when different polarity solvents were applied for the extraction of phenolic compounds (Abdelwahab et al. 2010; Kaur et al. 2008).

\section{Physicochemical characteristics of PRF-loaded nanoliposome}

The characteristics of nanoliposomes-loaded PRF are shown in Table 1. The particle size is an important factor in the stability and bioavailability of nanoliposomes. The particle size was $254.3 \pm 7.91 \mathrm{~nm}$ that displayed the nanometre size of the particles. As indicated in Table 3, the PDI values were reported $0.31 \pm 0.08$ indicating the homogenous dispersion (Hasan et al. 2014). The zeta potential values as the marker of the stability behavior of a colloid showed moderate stability of colloidal dispersion with the value of $-34.04 \pm 0.6 \mathrm{mV}$ based on the classification of Kumar et al. (Kumar and Dixit 2017). The FESEM image presented in Figure 1 displayed the spherical shape of nanoliposomes. The nanoliposome contained total phenolic compounds of $1.9 \pm 0.12 \mathrm{mg} \mathrm{GAE} / \mathrm{g}$ DW.

Table 1. Physical and phytochemical characteristics of nanoliposome-loaded by $A$. rosea phenolic rich fraction

\begin{tabular}{|llll} 
Particle size $(\mathrm{nm})$ & Polydispersity index (PDI) & Zeta potential $(\mathrm{mV})$ & $\begin{array}{l}\text { Total phenolics } \\
(\mathrm{mg} \mathrm{GAE} / \mathrm{g} \mathrm{DW})\end{array}$ \\
\hline $254.3 \pm 7.91$ & $0.31 \pm 0.08$ & $-34.04 \pm 0.6$ & $1.9 \pm 0.12$
\end{tabular}

\section{Phenolic compounds analysis}

The profiling of phenolic compounds presented in the nanoliposomes is shown in Table 2. The obtained results illustrated various types of phenolic compounds in the nanoliposomes whereas the cinnamic acid and gallic acid are the main and abundant phenolic compounds with the respective values of $805 \pm 8.2$ and $728.2 \pm 3.1 \mu \mathrm{g} / \mathrm{g}$ DW. 
Table 2. Phenolic compounds presented in the nanoliposome-loaded by $A$. rosea phenolic rich fraction

Phenolic compounds contents $(\mu \mathrm{g} / \mathrm{g}$ DW)

\begin{tabular}{lllllll}
\hline GA & SA & PY & CA & CT & NA & FE \\
\hline $728.2 \pm 3.1$ & $577 \pm 6.4$ & $411 \pm 6.5$ & $805 \pm 8.2$ & $236 \pm 5.7$ & $342 \pm 3.3$ & $221 \pm 6.2$
\end{tabular}

GA: gallic acid; SA: salicylic acid; PY: pyrogallol; CA: cinnamic acid; CT: catechin; NA: naringin; FE: ferulic acid. The analyses were performed in triplicates

\section{Animal trial}

The average daily weight gain and feed intake are shown in Table 3. The results revealed that the E. coli challenge (T2) impaired the daily weight gain and feed intake significantly $(p<0.05)$ as compared to the group of un-challenged mice ( $\mathrm{T} 1$ ). Moreover, the dietary addition of phytogenic compounds in the forms of nonencapsulated PRF and nanoliposome-encapsulated PRF in the groups of E. coli-challenged mice (T3 \& T4) improved these parameters significantly $(p<0.05)$. The results confirmed that dietary incorporation of phytogenic compounds in the form of nanoliposome-encapsulated PRF was more effective than in the form of nonencapsulated PRF in improving the daily weight gain and feed intake. The observed improvement in the daily weight gain and food intake at the presence of dietary phytogenic supplements could be associated to the antioxidant and antibacterial activity of bioactive compounds detected in the PRF such as gallic acid, salicylic acid, pyrogallol, cinnamic acid, catechin, naringin, ferulic acid.

Table 3. The averages of mice body weight changes and feed intake during experiment receiving different treatments

\begin{tabular}{llllll} 
Average & $\mathrm{T} 1$ & $\mathrm{~T} 2$ & $\mathrm{~T} 3$ & $\mathrm{~T} 4$ & SEM \\
\hline Average daily weight gain & $0.23^{\mathrm{a}}$ & $0.16^{\mathrm{cd}}$ & $0.18^{\mathrm{c}}$ & $0.21^{\mathrm{ab}}$ & 0.06 \\
\hline Average daily feed intake & $3.5^{\mathrm{a}}$ & $2.6^{\mathrm{c}}$ & $2.9^{\mathrm{bc}}$ & $3.1^{\mathrm{b}}$ & 0.12
\end{tabular}

T1: normal diet; T2: normal diet +infected by E. coli (0157:H7) on day $21 ; \mathrm{T} 3$ : Normal diet enriched by nonencapsulated phenolic rich fraction $(10 \mathrm{mg} \mathrm{TPC} / \mathrm{kg} \mathrm{BW} /$ day) + infected by E. coli $(0157: \mathrm{H7})$ on day 21; T4: Normal diet enriched by nanoliposome-encapsulated phenolic rich fraction (10 mg TPC/kg $\mathrm{BW} /$ day $)+$ infected by $E$. coli $(0157: \mathrm{H} 7)$ on day 21

Different letters in the same raw indicated significant difference $(p<0.05)$

The analysis were performed in triplicates

\section{Liver enzymes and lipid peroxidation analysis}


The results of liver enzymes analysis and lipid peroxidation in the liver tissue are presented in Table 4. Similar to the observation made in Table 3, the liver enzymes and lipid peroxidation increased significantly $(p<0.05)$ upon $E$. coli challenge when compared to the un-challenged group of mice. Further, the inclusion of nonencapsulated PRF and nanoliposome-encapsulated PRF alleviated the liver enzymes (SGOT, SGPT, ALP) and lipid peroxidation in the liver tissue significantly $(p<0.05)$. In line with the results observed in daily weight gain and food intake, providing PRF in the form of nanoliposome-encapsulated PRF was more effective in modulation of liver enzymes and lipid peroxidation as compared to the nonencapsulated PRF. In summary, these results postulated that enteropathogenic E. coil induced oxidative stress in the liver as indicated by lipid peroxidation and resulted in liver malfunction as shown by the increase in the liver enzymes. The antioxidant compounds detected in the PRF such as gallic acid, salicylic acid, pyrogallol, cinnamic acid, catechin, naringin, ferulic acid could alleviate the oxidative stress caused by $E$. coil and enhanced the function of the liver. Consistent with the results observed in this study early reports indicated the hepatoprotective activity of phenolic compounds against enteropathogens endotoxins (Saha et al. 2019).

Table 4. The results of liver enzymes analysis and lipid peroxidation in the liver tissue

\begin{tabular}{llllll}
\hline Parameters & T1 & T2 & T3 & T4 & SEM \\
\hline SGOT (IU/L) & $129.8^{\mathrm{d}}$ & $173.1^{\mathrm{a}}$ & $157.2^{\mathrm{b}}$ & $142.1^{\mathrm{c}}$ & 4.67 \\
\hline SGPT (IU/L) & $106.1^{\mathrm{d}}$ & $169.4^{\mathrm{a}}$ & $136.4^{\mathrm{b}}$ & $124.6^{\mathrm{c}}$ & 5.63 \\
\hline ALP (IU/L) & $147.3^{\mathrm{d}}$ & $215.6^{\mathrm{a}}$ & $171.4^{\mathrm{b}}$ & $158.9^{\mathrm{c}}$ & 7.42 \\
\hline MDA $^{*}(\%)$ & $100^{\mathrm{d}}$ & $173^{\mathrm{a}}$ & $156^{\mathrm{b}}$ & $142^{\mathrm{c}}$ & 4.49 \\
\hline
\end{tabular}

T1: normal diet; T2: normal diet +infected by E. coli $(0157: \mathrm{H} 7)$ on day $21 ; \mathrm{T} 3:$ Normal diet enriched by nonencapsulated phenolic rich fraction (10 mg TPC/kg BW/day) + infected by E. coli (0157: $\mathrm{H7})$ on day 21; T4: Normal diet enriched by nanoliposome-encapsulated phenolic rich fraction (10 mg TPC/kg BW/day) + infected by E. coli (0157:H7) on day 21

Different letters in the same raw indicated significant difference $(p<0.05)$

*Expressed as malondialdehyde changes relative to the control group ( $\mathrm{T} 1)$

The analysis were performed in triplicates

\section{Histopathology and morphometric analyses}

The histopathological characteristics of mice liver, kidney and ileum upon treatment by pathogenic bacteria, nonencapsulated PRF, and nanoliposome-encapsulated PRF are presented in Figure 2. The results showed normal architecture of the liver, kidney, and ileum in the control group (T1). The administration of $E$. coli $(0157: \mathrm{H7})$ in the days of 21 did not induce any prominent histomorphological changes in the liver and kidney tissues. Furthermore, it was obvious from the results that the treatment of 
mice challenged by E. coli (0157: $\mathrm{H7})$ bacteria using nonencapsulated PRF and nanoliposomeencapsulated PRF did not affect the histomorphology of the liver and kidney.

The morphometric analysis of ileum including villus height, villus width, and crypt depth and the number of goblet cells in treated mice are reported in Table 5. The mice challenged by $E$. coil showed a significant $(p<0.05)$ decrease in the villus height, villus width, and the numbers of goblet cells. The $E$. coilinfection increased the crypt depth significantly $(p<0.05)$. The dietary inclusion of $10 \mathrm{mg} \mathrm{TPC} / \mathrm{kg} \mathrm{BW} /$ day from nonencapsulated PRF and nanoliposome-encapsulated PRF significantly $(p<0.05)$ improved the villus height and width, crypt depth together with the number of goblet cells. These results were consistent with the early studies who reported the role of plant bioactive compounds in improving the morphostructure of ileum in enteropathogens infected or uninfected rabbit (Pogány Simonová et al. 2020) pig (Nofrarias et al. 2006) rat (Erlwanger and Cooper 2008) and broiler chickens (Khan et al. 2017).

Table 5. Morphometric analysis of ileum upon different treatments

\begin{tabular}{llllll}
\hline Parameters & T1 & T2 & T3 & T4 & SEM \\
\hline Villus Height $(\mu \mathrm{m})$ & $438.2^{\mathrm{a}}$ & $327.6^{\mathrm{d}}$ & $396.2^{\mathrm{c}}$ & $414.8^{\mathrm{b}}$ & 6.41 \\
\hline Villus Width $(\mu \mathrm{m})$ & $115.1^{\mathrm{a}}$ & $89.6^{\mathrm{d}}$ & $94.2^{\mathrm{c}}$ & $100.7^{\mathrm{b}}$ & 4.23 \\
\hline Crypt Depth $(\mu \mathrm{m})$ & $140.3^{\mathrm{d}}$ & $192.8^{\mathrm{a}}$ & $182.1^{\mathrm{b}}$ & $169.7^{\mathrm{c}}$ & 4.66 \\
\hline Mean number of Goblet cells & $5.5^{\mathrm{a}}$ & $3.7^{\mathrm{c}}$ & $4.3^{\mathrm{b}}$ & $4.4^{\mathrm{b}}$ & 0.47 \\
\hline
\end{tabular}

T1: normal diet; T2: normal diet +infected by E. coli $(0157: \mathrm{H} 7)$ on day $21 ; \mathrm{T} 3$ : Normal diet enriched by a nonencapsulated phenolic rich fraction $(10 \mathrm{mg} \mathrm{TPC} / \mathrm{kg} \mathrm{BW} /$ day $)+$ infected by $E$. coli $(0157: \mathrm{H} 7)$ on day 21; T4: Normal diet enriched by nanoliposome-encapsulated phenolic rich fraction (10 mg TPC/kg BW/day) + infected by E. coli (0157:H7) on day 21

Different letters in the same raw indicated significant difference $(p<0.05)$

The analysis were performed in triplicates

\section{Gene expression analysis}

The expression of COX2 and iNOS as major biomarkers of inflammation and SOD and GPx genes as biomarkers of antioxidant activity in the ileum are shown in Table 6. The infection caused by E. coil (T2) significantly $(p<0.05)$ up-regulated the expression of COX2 and iNOS and down-regulated the expression of SOD and GPx as compared to uninfected mice (T1). The dietary addition of $10 \mathrm{mg} \mathrm{TPC} / \mathrm{kg} \mathrm{BW} /$ day from nonencapsulated PRF and nanoliposome-encapsulated PRF could significantly $(p<0.05)$ suppressed the COX2 and iNOS as inflammatory markers and enhanced the expression of SOD and GPx genes as an indicator of cellular antioxidant redox potential. The regulation of inflammatory- and antioxidant-related genes is attributed to the anti-inflammatory and antioxidant activities of bioactive compounds detected in 
the PRF such as gallic acid, salicylic acid, pyrogallol, cinnamic acid, catechin, naringin, ferulic acid (Rubió et al. 2013).

Table 6. Gene expression analysis of the mice received different treatments

\begin{tabular}{llllll}
\hline \multicolumn{2}{c}{ Fold changes } & \multicolumn{2}{c}{ SEM } \\
\cline { 1 - 2 } Genes & T1 & T2 & T3 & T4 & \\
\hline COX2 & $1.0^{\mathrm{d}}$ & $+5.1^{\mathrm{a}}$ & $+3.1^{\mathrm{b}}$ & $+1.1^{\mathrm{c}}$ & 0.06 \\
\hline iNOS & $1.0^{\mathrm{d}}$ & $+3.1^{\mathrm{a}}$ & $+2.2^{\mathrm{b}}$ & $+1.3^{\mathrm{c}}$ & 0.17 \\
\hline SOD & $1.0^{\mathrm{c}}$ & $-1.3^{\mathrm{d}}$ & $+1.2^{\mathrm{b}}$ & $+1.9^{\mathrm{a}}$ & 0.09 \\
\hline GPx & $1.0^{\mathrm{c}}$ & $-1.6^{\mathrm{d}}$ & $+0.4^{\mathrm{b}}$ & $+1.3^{\mathrm{a}}$ & 0.14 \\
\hline
\end{tabular}

T1: normal diet; T2: normal diet +infected by E. coli $(0157: \mathrm{H} 7)$ on day $21 ; \mathrm{T} 3$ : Normal diet enriched by nonencapsulated phenolic rich fraction $(10 \mathrm{mg}$ TPC/ $\mathrm{kg} \mathrm{BW} /$ day) + infected by $E$. coli $(0157: \mathrm{H7})$ on day 21; T4: Normal diet enriched by nanoliposome-encapsulated phenolic rich fraction $(10 \mathrm{mg} T P C / \mathrm{kg}$ BW/day) + infected by E. coli (0157: $\mathrm{H7})$ on day 21

Different letters in the same column indicated a significant difference $(p<0.05)$

The analysis was performed in triplicates

\section{E. coil population analysis}

Figure 3 illustrated the relative changes in the E. coil population upon different treatments. As compared to the uninfected mice, the population of $E$. coil in the ileum of infected mice increased significantly $(p<0.05)$ by 12.6 folds. The dietary supplementation of nonencapsulated PRF and nanoliposomeencapsulated PRF significantly $(p<0.05)$ modulated the population of $E$. coil in the ileum by 7.9 and 4.4 folds, respectively. It seemed that nanoliposome-encapsulated PRF was more potent in inhibiting the population of enteropathogenic E. coil in the ileum as compared to the nonencapsulated PRF. Hence, the nanoliposome-encapsulated PRF could play a role as promising phytobiotic against $E$. coil infection in mice. The inhibition of $E$. coli in the ileum by nanoliposome-encapsulated PRF might be due to the antibacterial activity of bioactive phenolics including gallic acid, salicylic acid, pyrogallol, cinnamic acid, catechin, naringin and ferulic acid in the PRF (Bouarab-Chibane et al. 2019).

\section{Conclusion}

The dietary inclusion of nonencapsulated PRF and nanoliposome-encapsulated PRF at the concentration of $10 \mathrm{mg} \mathrm{TPC} / \mathrm{kg} \mathrm{BW} /$ day improved the health parameters in the mice challenged by enteropathogenic $E$. coli, however, the nanoliposome-encapsulated PRF appeared to be more effective as compared to nonencapsulated PRF in improving the health parameters. Consequently, the nanoliposome-encapsulated PRF could play a critical role as a promising phytobiotic against $E$. coil infection in mice. 


\section{Materials And Methods}

\section{Plant material and reagents}

The fresh leaves of $A$. rosea were purchased from the herbal medicine market of Mashhad, Iran. The soybean lecithin (purity of 99\%) was purchased from Sigma Aldrich (Germany). The E. coli (0157: H7) as a food-borne pathogen was obtained from the microbial culture collection of Islamic Azad University of Mashhad, Iran. For the gene expression analysis the RNeasy Mini kit (Qiagen, Hilden, Germany), cDNA synthesis Quantitect Reverse Transcription kit (Qiagen, Hilden, Germany), and SYBR Green PCR Master Mix (Qiagen, Hilden, Germany) were used. The DNA extraction kit used in this study was QIAamp DNA Stool Mini Kit from Qiagen GmbH, Hilden, Germany. The other reagents not mentioned here were from Merck (Germany).

\section{Fractionation and total phenolic determination}

In the first step, the fresh leaves were cleaned by sterile distilled water, dried in shadow for two weeks in room temperature. The dried leaves finely ground (powder form) using a grinder mill. Then, the $100 \mathrm{~g}$ of the dried powder was extracted with $900 \mathrm{~mL}$ aqueous methanol $(80 \%(\mathrm{v} / \mathrm{v}))$ and $100 \mathrm{~mL}$ of $6 \mathrm{M} \mathrm{HCl}$ using the reflux method for 2 hours (Karimi et al. 2019). Finally, the extract was filtered and the filtrate was evaporated at the temperature of $60^{\circ} \mathrm{C}$ by rotary evaporator (Buchi, Flawil, Switzerland). In the second step, the dried aqueous-methanolic extract was fractionated using separating funnel and different solvents including hexane, chloroform, ethyl acetate, n-butanol, and water-based on the Oskoueian et al (Oskoueian et al. 2020). Upon fractionation, the supernatant was filtered and concentrated using a vacuumed rotary evaporator. The total phenolic compounds (TPC) evaluation of each fraction was carried out by adding $0.1 \mathrm{ml}$ of the extract, $2.5 \mathrm{ml}$ of Folin-Ciocalteu reagent (1:10 v/v), and $2 \mathrm{ml}$ of $7.5 \%$ sodium carbonate into a test tube covered with aluminum foil. The test tubes were vortexed and the absorbance was measured at $765 \mathrm{~nm}$ (Oskoueian et al. 2020). The results were expressed as milligrams of gallic acid equivalents (GAE) per gram dry weight. The fraction containing the highest phenolic content is named as a phenolic rich fraction (PRF).

\section{Nanoliposomes preparation}

The four grams of lecithin were agitated for $2 \mathrm{~h}$ by $196 \mathrm{~g}$ of hot water $\left(80^{\circ} \mathrm{C}\right)$ using stirrer at $300 \mathrm{rpm}$. Then, the PRF after dissolving in ethanol was added to the mixture and stirred for $2 \mathrm{~h}$ to reach the final concentration of $2000 \mathrm{ppm}$. Finally, the solution was bath-sonicated at 80\% power (Sonorex RK100, Germany) during 4 to 6 minutes and the obtained nanoliposomes-loaded PRF from A. rosea was prepared and used for further characterization.

\section{Characterization of nanoliposomes}

At the beginning, the nanoliposomes-loaded PRF was diluted by water (1:20) to decrease the aggregation and inhibit the noise scattering. The dynamic light scattering (DLS) method was performed to determine 
the average size of particles and their stability (zeta potential). The measurements were analyzed three times by a Malvern Zetasizer Nano ZS (Malvern, UK). Moreover, Field Emission Scanning Electron Microscopy (FESEM) was applied to verify the shape and nanoliposomes size dimensions. The total phenolic content of nanoliposomes was determined as described earlier in the fractionation section (Oskoueian et al. 2020).

\section{Phenolic profiling of nanoliposomes}

The Reversed-Phase High-Performance Liquid Chromatography (RP-HPLC) analysis was carried out to investigate the types of phenolic compounds present in the nanoliposomes. Briefly, the solvents comprising of deionized water (solvent $\mathrm{A}$ ) and acetonitrile (solvent $\mathrm{B}$ ), the $\mathrm{pH}$ of solvent $\mathrm{A}$ was adjusted to 2.5 using concentrated trifluoroacetic acid. The column was equilibrated by $85 \%$ solvent $A$ and $15 \%$ solvent $B$ for 15 min before injection. Then, the ratio of solvent $B$ was increased to $85 \%$ after 50 min. After 5 min (at the $55^{\text {th }}$ minute of running the experiment), the ratio of solvent $B$ was reduced to $15 \%$. This ratio was maintained for $60 \mathrm{~min}$ for the next analysis with a flow rate of $1 \mathrm{ml} / \mathrm{min}$. An analytical column (Intersil ODS-3 5um 4.6×150 mm GI Science Inc. USA) was used for the detection of phenolic at $280 \mathrm{~nm}$. The phenolic standards used in this study were gallic acid, syringic acid, vanillic acid, salicylic acid, caffeic acid, pyrogallol, catechin, cinnamic acid, ellagic acid, naringin, chrysin, and ferulic acid.

\section{Animal trial}

The 40 white male Balb/c mice (20-25 g) were obtained from the Razi vaccine and serum research institute of Mashhad. The mice were kept in the individual cages at $58 \% \pm 10 \%$ humidity and $23^{\circ} \mathrm{C} \pm 1^{\circ} \mathrm{C}$ with 12-hour light/dark periods for 7 days to be adapted with lab condition. We divided the mice into four groups of ten. With free access to the standard pellet diet (Javaneh Khorasan, Mashhad, Iran) and tap water. The experimental treatments were as follow:

T1: normal diet

T2: normal diet +infected by E. coli (0157: $\mathrm{H7})$ on day 21

T3: Normal diet enriched by nonencapsulated PRF (10 mg TPC/kg BW/day) + infected by E. coli (0157: H7) on day 21

T4: Normal diet enriched by nanoliposome-encapsulated PRF (10 mg TPC/kg BW/day) + infected by $E$. coli (0157: H7) on day 21

All mice received experimental treatments for 4 weeks and the oral infection through gavage needle $\left(10^{8}\right.$ CFU of Escherichia coli 0157: H7) was conducted for once on day 21. Animals were monitored daily for general health and the amount of food eaten. At the end of the experiment (day 28), the mice were euthanized with pentobarbital-HCL (50 mg/kg, i.p.) and sacrificed. The blood, liver, and ileum samples were collected immediately and used for liver enzyme analysis, lipid peroxidation assay, gene expression analysis, and morphometric evaluation of ileum, respectively. The mice were weighed three times at the 
beginning, middle, and at the end of the experiment. All animal experiments were conducted according to the ethical principles approved by the Islamic Azad University of Mashhad with the code of ethics IR.IAU.MSHD.REC.1399.016.

\section{Liver enzymes and lipid peroxidation assay}

The main liver enzymes in the serum including alanine aminotransferase (ALT), aspartate transaminase (AST), and alkaline phosphatase (ALP) were determined using blood auto-analyzer (Hitachi 902, Japan). The lipid peroxidation in the liver tissue was determined as described earlier by Shafaei et al. (Shafaei et al. 2020). Briefly, the liver tissue was homogenized and $200 \mu \mathrm{l}$ of lysate were mixed by distilled water (300 $\mu \mathrm{l}), \mathrm{BHT}(35 \mu \mathrm{l})$, sodium dodecyl sulfate $(165 \mu \mathrm{l})$ and thiobarbituric acid $(2 \mathrm{ml})$ respectively. Then, after heating $\left(90^{\circ} \mathrm{C}\right.$ for $\left.60 \mathrm{~min}\right)$ the cooled solution was mixed by $2 \mathrm{~mL}$ of $\mathrm{n}$-butanol and centrifuged at 2000 $\mathrm{xg}$ for $5 \mathrm{~min}$. Finally, the absorbance of the $\mathrm{n}$-butanol part was read at $532 \mathrm{~nm}$ and the results were expressed as percentage malondialdehyde (MDA) changes relative to the control.

\section{Histopathology and morphometric analyses}

At the end of the in vivo experiment, the mice were sacrificed and the liver, kidney, and ileum were separated and washed using the physiological serum. Then, they were fixed in buffered formalin $(10 \%$ formalin in $0.1 \mathrm{M}$ sodium phosphate buffer, $\mathrm{pH} 7$ ). Finally, they were paraffinized, sliced, and stained according to the hematoxylin/eosin protocol (Shafaei et al. 2020). The histopathology slides were observed under a light microscope using a magnification of 20X. The morpho-structural characteristics of ileum including villus height, villus width, crypt depth, and goblet cell count were determined (Navarrete et al. 2015).

\section{Gene expression analysis}

To investigate the response of ileum tissue to different treatments, the expression of major inflammation biomarker genes such as cyclooxygenase 2 (COX2), inducible nitric oxide synthase (iNOS) and antioxidant-related genes including superoxide dismutase (SOD) and glutathione peroxidase (GPX) were determined. The mice's ileum tissues which were freshly frozen in the liquid nitrogen, crushed and prepared for RNA extraction by an RNeasy Mini kit (Qiagen, Hilden, Germany) following the recommended protocols. Then, cDNA was synthesized using a Quantitect Reverse Transcription kit (Qiagen, Hilden, Germany). Next, the sets of primer sequences for the key genes and a housekeeping (Beta-actin) gene were applied in the experiment as shown in Table 1. The SYBR Green PCR Master Mix (Qiagen, Hilden, Germany) was used in a comparative Real-time PCR (Roche Diagnostics). The targeted genes were amplified as follows: $95^{\circ} \mathrm{C}$ for $5 \mathrm{~min}(1 \mathrm{X})$ for initial denaturation, followed by 35 cycles of $95^{\circ} \mathrm{C}$ for $30 \mathrm{~s}$, primer annealing at 60 and 58 for 30 s for the inflammatory genes and antioxidant genes, respectively and extension of $72^{\circ} \mathrm{C}$ for $30 \mathrm{~s}$. The expressions of genes were normalized to beta-actin as a reference gene and then normalized to the expression of respective genes in the control group (Kathirvel et al. 2010). The characteristics of the primer used in this study are presented in Table 7. 
Table 7. The primer sets characteristics used in this study.

\begin{tabular}{llll}
\hline Gene & Forward $\left(5^{\prime} \rightarrow 3^{\prime}\right)$ & Reverse $\left(5^{\prime} \rightarrow 3^{\prime}\right)$ & References \\
\hline COX2 & caagcagtggcaaaggcctcca & ggcacttgcattgatggtggct & (Jain et al. 2008) \\
\hline iNOS & caccttggagttcacccagt & accactcgtacttgggatgc & (Kou et al. 2011) \\
\hline SOD & gagacctgggcaatgtgact & gtttactgcgcaatcccaat & (Kathirvel et al. 2010) \\
\hline GPX & caagttttgatgccctggt & tcggacgtacttgagggaat & (Kathirvel et al. 2010) \\
\hline -actin & cctgaaccctaaggccaacc & cagctgtggtggtgaagctg & (Shafaei et al. 2020)
\end{tabular}

\section{E. coil population analysis}

The real-time PCR (LightCycler 96 instrument, Roche, Basel, Switzerland) was used to determine the fold changes of E. coli $(0157: \mathrm{H} 7)$ population in the ileum digesta. Since the major sites of microbial fermentation and propagation and colonization of enteropathogens in the monogastric is the ileum, that is why in this study the population of $E$. coil was analyzed only in the ileum section. The real-time PCR condition was $95^{\circ} \mathrm{C}$ for $5 \mathrm{~min}(1 \mathrm{X})$ for initial denaturation, followed by 35 cycles of $95^{\circ} \mathrm{C}$ for $30 \mathrm{~s}$, primer annealing at 60 , and 55 for $25 \mathrm{~s}$ for the E. coil and total bacteria, respectively and extension of $72^{\circ} \mathrm{C}$ for 20s. The primer characteristics are shown in Table 8. The DNA from ileum digesta was extracted using QIAamp DNA Stool, extraction kit (QIAGEN, Germany). The SYBR GREEN Master Mix (BIOFACT, Korea) was used in this study. The previously published primers were used for quantitative real-time PCR assay. The real-time PCR data were analyzed using $\Delta \Delta$ Ct method to determine the fold changes in the $E$. coli bacteria population and the data were expressed as fold changes of $E$. coil relative to the total bacteria (Feng et al. 2010; Si et al. 2007).

Table 8. The list of the primers used for ileum microbial population analysis

\begin{tabular}{llll} 
Bacteria & Forward $\left(\mathbf{5}^{\prime} \rightarrow \mathbf{3}^{\prime}\right)$ & Reverse $\left(\mathbf{5}^{\prime} \rightarrow \mathbf{3}^{\prime}\right)$ & References \\
\hline $\begin{array}{l}\text { E. } \\
\text { coli }(0157: \mathrm{H7})\end{array}$ & ttaccagcgataccaagagc & caacatgaccgatgacaagg & (Si et al. 2007) \\
\hline Total bacteria & cggcaacgagcgcaaccc & $\begin{array}{l}\text { ccattgtagcacg } \\
\text { tgtgtagcc }\end{array}$ & $\begin{array}{l}\text { (Denman and McSweeney } \\
\text { 2006) }\end{array}$ \\
\hline
\end{tabular}

\section{Statistical Analysis}

The data obtained were subjected to the general linear models (GLM) procedure of SAS [(9.1) (20022003) (SAS Institute Inc., Cary, NC, USA)] in a completely randomized design (CRD) and the means were compared with Duncan's Multiple Range Test. The difference was considered significant when the Pvalue was $<0.05$. 


\section{Declarations}

Acknowledgements

The authors are grateful to the Islamic Azad University of Mashhad for the laboratory facilities.

\section{Authors' contributions}

$\mathrm{NH}$ : Study design, experimental work and writing original draft; EK and EO: analysis, methodology, project administration, supervision, review, and editing of the original draft; All authors read and approved the final manuscript.

\section{Funding}

There has been no financial support for this work.

\section{Availability of data and materials}

The datasets applied during the current study are available on reasonable request.

\section{Ethics approval and consent to participate}

All protocols to use the invivo study were reviewed and reported in accordance with ARRIVE guidelines. All animal experiments were conducted according to the ethical principles approved by the Islamic Azad University of Mashhad, IRAN with the code of ethics IR.IAU.MSHD.REC.1399.016.

\section{Consent to Participate:}

Not applicable

\section{Consent to Publication:}

Not applicable

\section{Competing interests}

The authors declare that they have no competing interests.

\section{References}

1. Abdel-salam NA, Ghazy NM, Sallam SM et al (2018) Flavonoids of Alcea rosea L. and their immune stimulant, antioxidant and cytotoxic activities on hepatocellular carcinoma HepG-2 cell line. Nat Prod Res 32:702-706

2. Abdelwahab SI, Mohan S, Mohamed Elhassan M et al (2010) Antiapoptotic and antioxidant properties of Orthosiphon stamineus benth (Cat's Whiskers): intervention in the Bcl-2-mediated 
apoptotic pathway Evidence-Based Complementary and Alternative Medicine 2011

3. Acosta-Estrada BA, Gutiérrez-Uribe JA, Serna-Saldívar SO (2014) Bound phenolics in foods. a review Food chemistry 152:46-55

4. Aditya N, Espinosa YG, Norton IT (2017) Encapsulation systems for the delivery of hydrophilic nutraceuticals. Food application Biotechnology advances 35:450-457

5. Anand S, Deighton M, Livanos G et al (2019) Antimicrobial activity of Agastache honey and characterization of its bioactive compounds in comparison with important commercial honeys. Frontiers in microbiology 10:263

6. Azab A (2017) Alcea: Traditional medicine, current research and future opportunities. Eur Chem Bull 5:505-514

7. Bouarab-Chibane L, Forquet V, Lantéri P et al (2019) Antibacterial properties of polyphenols: characterization and QSAR (Quantitative structure-activity relationship) models Frontiers in microbiology 10:829

8. Cianciosi D, Forbes-Hernández TY, Afrin S et al (2018) Phenolic compounds in honey and their associated health benefits. A review Molecules 23:2322

9. Denman SE, McSweeney CS (2006) Development of a real-time PCR assay for monitoring anaerobic fungal and cellulolytic bacterial populations within the rumen. FEMS MicrobiolEcol 58:572-582

10. Emami S, Azadmard-Damirchi S, Peighambardoust SH et al (2016) Liposomes as carrier vehicles for functional compounds in food sector. J Exp Nanosci 11:737-759

11. Erlwanger $K$, Cooper R (2008) The effects of orally administered crude alcohol and aqueous extracts of African potato (Hypoxis hemerocallidea) corm on the morphometry of viscera of suckling rats. Food chemical toxicology 46:136-139

12. Feng Y, Gong J, Yu H et al (2010) Identification of changes in the composition of ileal bacterial microbiota of broiler chickens infected with Clostridium. perfringens Veterinary microbiology 140:116-121

13. Fischbach MA, Walsh CT (2009) Antibiotics for emerging pathogens. Science 325:1089-1093

14. Friedman ND, Temkin E, Carmeli Y (2016) The negative impact of antibiotic resistance Clinical. Microbiology Infection 22:416-422

15. Frieri M, Kumar K, Boutin A (2017) Antibiotic resistance Journal of infection public health 10:369378

16. Górniak I, Bartoszewski R, Króliczewski J (2019) Comprehensive review of antimicrobial activities of plant flavonoids. Phytochem Rev 18:241-272

17. Gutiérrez-del-Río I, Fernández J, Lombó F (2018) Plant nutraceuticals as antimicrobial agents in food preservation: terpenoids. polyphenols thiols International journal of antimicrobial agents 52:309315

18. Hadi MY, Hameed IH, Ibraheam IA (2017) Mentha pulegium: Medicinal uses, Anti-Hepatic, Antibacterial, Antioxidant effect and Analysis of Bioactive Natural Compounds: A Review Research. 
Journal of Pharmacy Technology 10:3580-3584

19. Hasan M, Belhaj N, Benachour H et al (2014) Liposome encapsulation of curcumin: physicochemical characterizations and effects on MCF7 cancer. cell proliferation 461:519-528

20. Hwang IY, Koh E, Wong A et al (2017) Engineered probiotic Escherichia coli can eliminate and prevent Pseudomonas aeruginosa gut infection in animal models. Nature communications 8:1-11

21. Jain NK, Ishikawa T-o, Spigelman I et al (2008) COX-2 expression and function in the hyperalgesic response to paw inflammation in mice Prostaglandins. leukotrienes essential fatty acids 79:183190

22. Karimi E, Mehrabanjoubani P, Es-Haghi A et al (2019) Phenolic Compounds of Endemic Buxus Plants in Caspian Hyrcanian Forest (Buxus Hyrcana Pojark) and Their Biological Activities. Pharm Chem J 53:741-747

23. Kathirvel E, Chen P, Morgan $\mathrm{K}$ et al (2010) Oxidative stress and regulation of anti-oxidant enzymes in cytochrome P4502E1 transgenic mouse model of non-alcoholic fatty liver. Journal of gastroenterology hepatology 25:1136-1143

24. Kaur R, Arora S, Singh B (2008) Antioxidant activity of the phenol rich fractions of leaves of Chukrasia tabularis A. Juss Bioresource Technology 99:7692-7698. doi:https://doi.org/10.1016/j.biortech.2008.01.070

25. Khan I, Zaneb H, Masood S et al (2017) Effect of Moringa oleifera leaf powder supplementation on growth performance and intestinal morphology in broiler chickens. J Anim Physiol Anim Nutr 101:114-121

26. Khoshnamvand M, Ashtiani S, Huo C et al (2019) Use of Alcea rosea leaf extract for biomimetic synthesis of gold nanoparticles with innate free radical scavenging and catalytic activities. J Mol Struct 1179:749-755

27. Kou X, Qi S, Dai W et al (2011) Arctigenin inhibits lipopolysaccharide-induced iNOS expression in RAW264. 7 cells through suppressing JAK-STAT signal. pathway International Immunopharmacology 11:1095-1102

28. Kumar A, Dixit CK (2017) Methods for characterization of nanoparticles. In: Advances in nanomedicine for the delivery of therapeutic nucleic acids. Elsevier, pp 43-58

29. Mostafa AA, Al-Askar AA, Almaary KS et al (2018) Antimicrobial activity of some plant extracts against bacterial strains causing food poisoning diseases Saudi. Journal of Biological Sciences 25:361-366

30. Navarrete J, Vásquez B, Del Sol M (2015) Morphoquantitative analysis of the lleum of C57BL/6 mice (Mus musculus) fed with a high-fat diet. Int J Clin Exp Pathol 8:14649

31. Nofrarias M, Manzanilla E, Pujols J et al (2006) Effects of spray-dried porcine plasma and plant extracts on intestinal morphology and on leukocyte cell subsets of weaned pigs. J Anim Sci 84:2735-2742

32. Oskoueian E, Karimi E, Noura R et al (2020) Nanoliposomes encapsulation of enriched phenolic fraction from pistachio hulls and its antioxidant, anti-inflammatory, and anti-melanogenic activities. 
J Microencapsul 37:1-13

33. Ozkan G, Franco P, De Marco I et al (2019) A review of microencapsulation methods for food antioxidants: Principles, advantages, drawbacks and applications Food chemistry 272:494-506

34. Pogány Simonová M, Chrastinová L', Kandričáková A et al (2020) Can Enterocin M in Combination with Sage Extract Have Beneficial Effect on Microbiota, Blood Biochemistry, Phagocytic Activity and Jejunal Morphometry. Broiler Rabbits? Animals 10:115

35. Rubió L, Motilva M-J, Romero M-P (2013) Recent advances in biologically active compounds in herbs and spices: a review of the most effective antioxidant and anti-inflammatory active principles. Critical reviews in food science nutrition 53:943-953

36. Saha P, Talukdar AD, Nath R et al (2019) Role of natural phenolics in hepatoprotection: A mechanistic review and analysis of regulatory network of associated genes Frontiers in pharmacology 10:509

37. Salimi A (2018) Liposomes as a novel drug delivery system: fundamental and pharmaceutical application Asian Journal of Pharmaceutics (AJP): Free full text articles from Asian J Pharm 12

38. Shafaei N, Barkhordar SMA, Rahmani F et al (2020) Protective Effects of Anethum graveolens Seed's Oil Nanoemulsion Against Cadmium-Induced Oxidative Stress in Mice Biological Trace Element Research:1-9

39. Si C, Kun-Lun H, Wen-Tao X et al (2007) Real-time quantitative PCR detection of Escherichia coli 0157: H7 Chinese. Journal of Agricultural Biotechnology 4:15-19

40. Vadhana P, Singh B, Bharadwaj M et al (2015) Emergence of herbal antimicrobial drug resistance in clinical bacterial isolates. Pharm Anal Acta 6:434

\section{Figures}




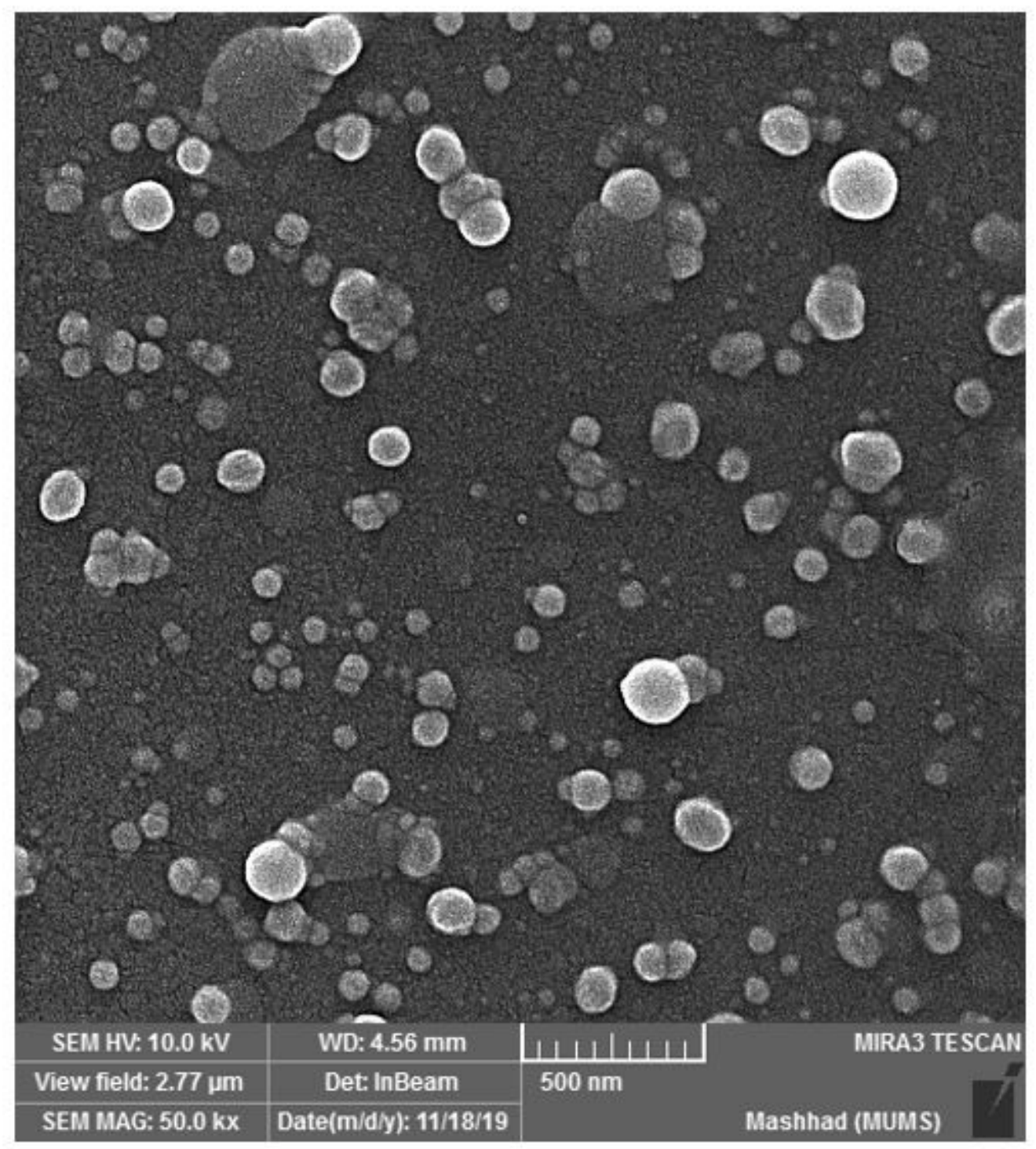

\section{Figure 1}

The FESEM analysis of nanoliposome-loaded by A. rosea phenolic rich fraction 
T1

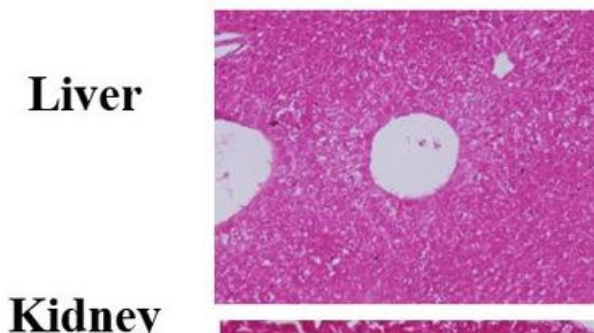

Kidney

\section{Ileum}
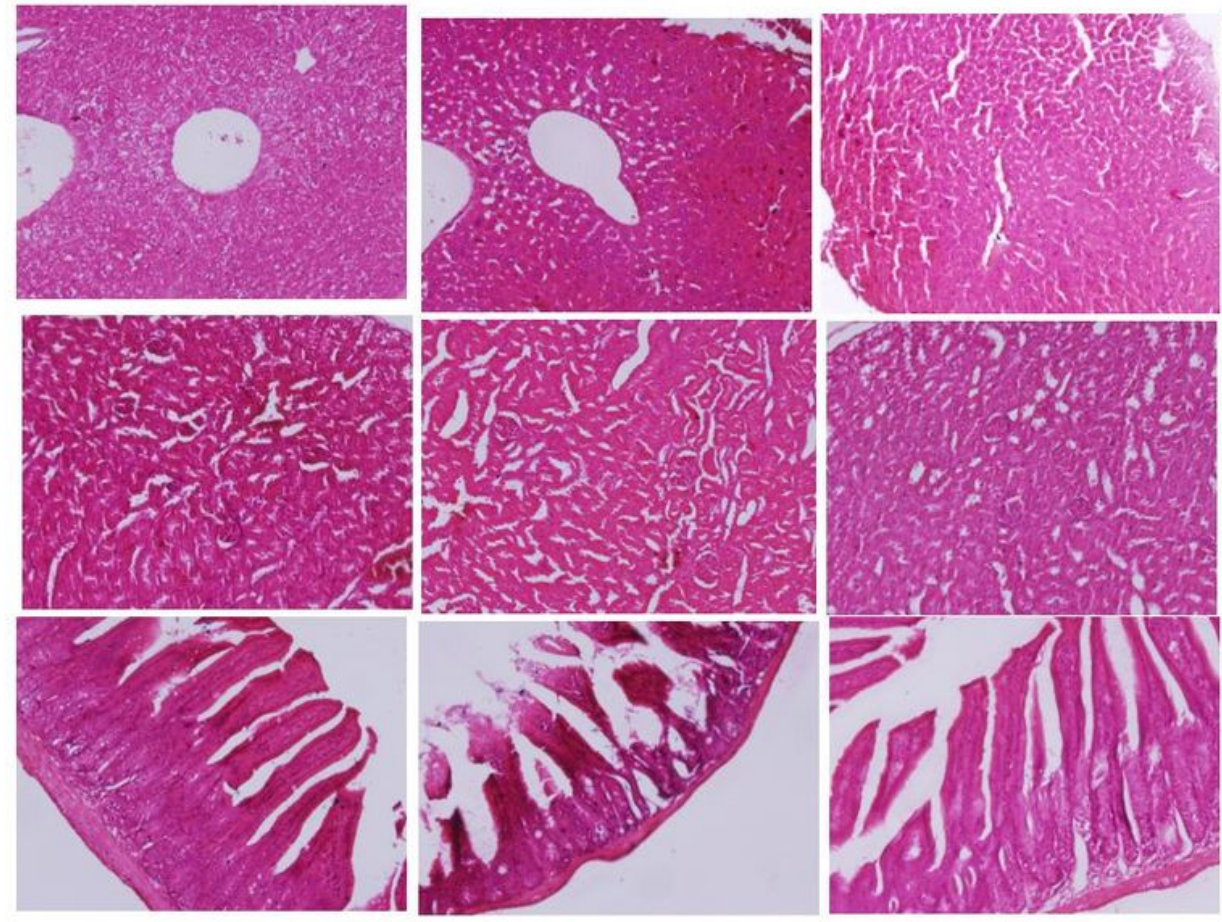

T4

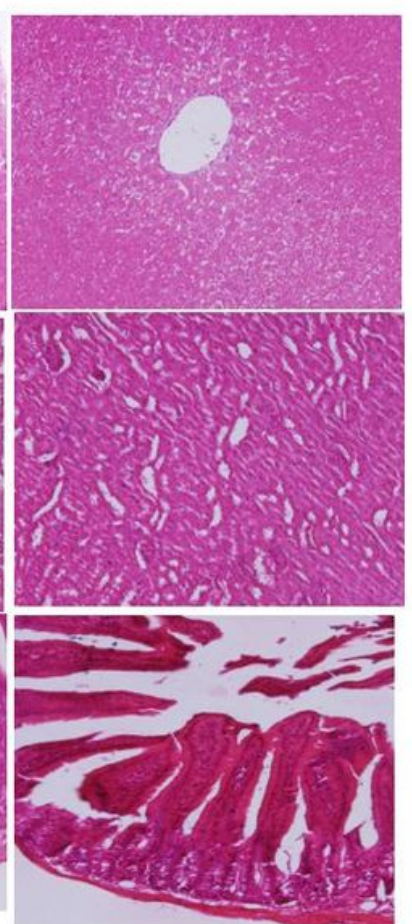

\section{Figure 2}

Histopathological analysis of the liver, kidney, and ileum of the mice undergone different treatments. T1: normal diet; T2: normal diet +infected by E. coli (0157: H7) on day 21; T3: Normal diet enriched by a nonencapsulated phenolic rich fraction (10 mg TPC/kg BW/day) + infected by E. coli (0157: H7) on day 21; T4: Normal diet enriched by nanoliposome-encapsulated phenolic rich fraction (10 mg TPC/ $\mathrm{kg}$ BW/day) + infected by E. coli (0157: H7) on day 21 


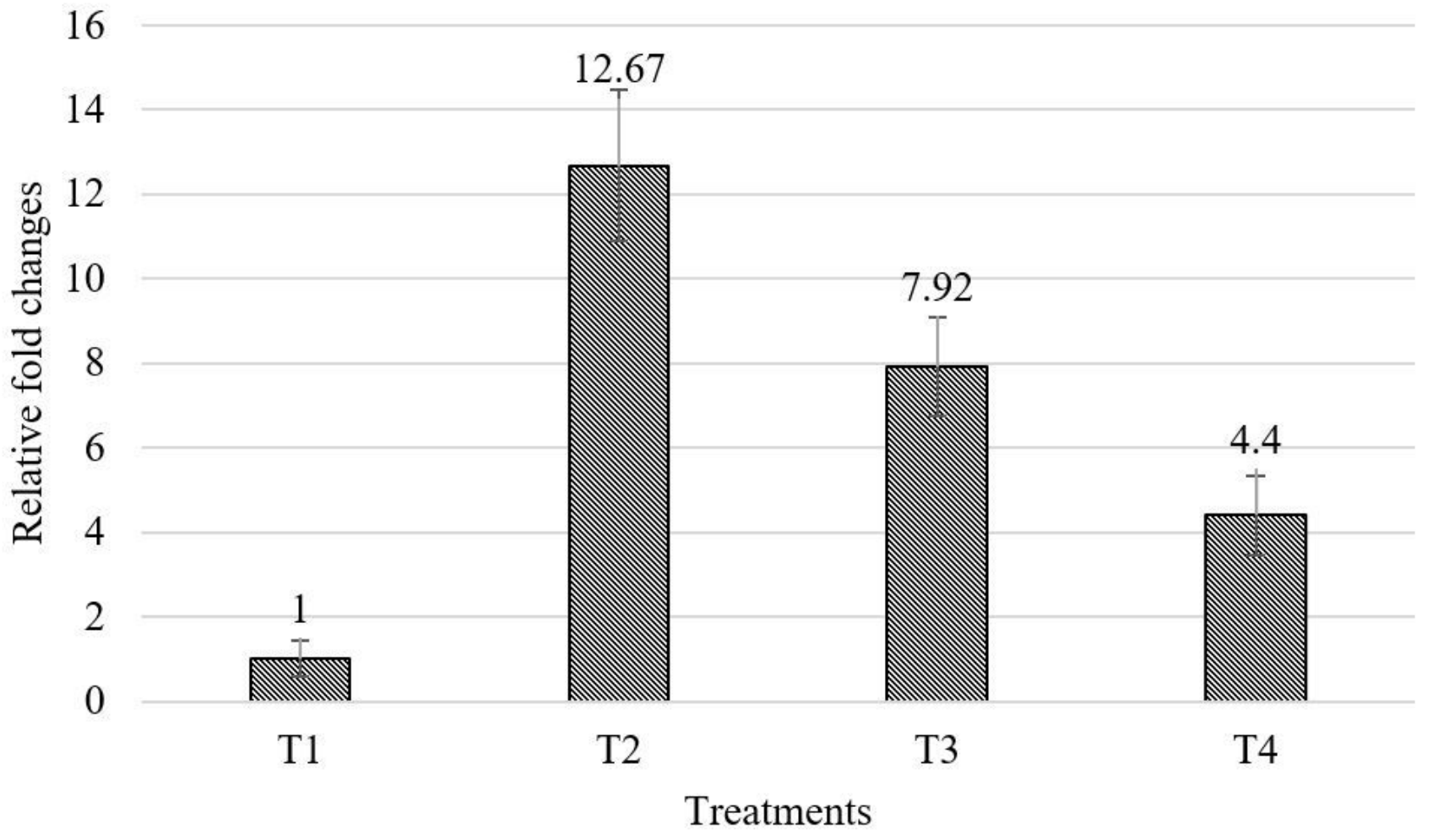

Figure 3

Relative fold changes in the ileum population of E. coli (0157: H7). T1: normal diet; T2: normal diet +infected by E. coli (0157: H7) on day 21; T3: Normal diet enriched by nonencapsulated phenolic rich fraction (10 mg TPC/kg BW/day) + infected by E. coli (0157: H7) on day 21; T4: Normal diet enriched by nanoliposome-encapsulated phenolic rich fraction (10 mg TPC/kg BW/day) + infected by E. coli (0157: H7) on day 21 